OPEN ACCESS

Edited by:

Mauricio Antonio Retamal, Universidad del Desarrollo, Chile

Reviewed by:

Felipe Yasser Eltit,

The University of British Columbia,

Canada

Claudio Esteban Perez-Leighton,

Pontificia Universidad Católica de Chile, Chile

${ }^{*}$ Correspondence: Felipe Simon

fsimon@unab.c

Pablo Olivero

pablo.olivero@uv.cl

Specialty section: This article was submitted to Membrane Physiology and Membrane Biophysics, a section of the journal

Frontiers in Physiology

Received: 06 February 2018 Accepted: 16 May 2018

Published: 05 June 2018

Citation:

Ramírez-Barrantes $R$, Córdova $C$ Gatica S, Rodriguez B, Lozano C, Marchant I, Echeverria C, Simon F and Olivero P (2018) Transient Receptor Potential Vanilloid 1 Expression Mediates Capsaicin-Induced Cell Death Front. Physiol. 9:682. doi: 10.3389/fphys.2018.00682

\section{Transient Receptor Potential Vanilloid 1 Expression Mediates Capsaicin-Induced Cell Death}

\author{
Ricardo Ramírez-Barrantes', Claudio Córdova1, Sebastian Gatica ${ }^{2,3}$, Belén Rodriguez', \\ Carlo Lozano', Ivanny Marchant ${ }^{1}$, Cesar Echeverria ${ }^{4}$, Felipe Simon ${ }^{2,3 *}$ and \\ Pablo Olivero ${ }^{1 *}$
}

'Laboratorio de Estructura y Función Celular, Escuela de Medicina, Facultad de Medicina, Universidad de Valparaíso, Valparaíso, Chile, ${ }^{2}$ Departamento de Ciencias Biologicas, Facultad de Ciencias de la Vida, Universidad Andres Bello, Santiago, Chile, ${ }^{3}$ Millennium Institute on Immunology and Immunotherapy, Santiago, Chile, ${ }^{4}$ Centro Integrativo de Biología y Química Aplicada, Universidad Bernardo O'Higgins, Santiago, Chile

The transient receptor potential (TRP) ion channel family consists of a broad variety of non-selective cation channels that integrate environmental physicochemical signals for dynamic homeostatic control. Involved in a variety of cellular physiological processes, TRP channels are fundamental to the control of the cell life cycle. TRP channels from the vanilloid (TRPV) family have been directly implicated in cell death. TRPV1 is activated by pain-inducing stimuli, including inflammatory endovanilloids and pungent exovanilloids, such as capsaicin (CAP). TRPV1 activation by high doses of CAP (>10 $\mu \mathrm{M})$ leads to necrosis, but also exhibits apoptotic characteristics. However, CAP dose-response studies are lacking in order to determine whether CAP-induced cell death occurs preferentially via necrosis or apoptosis. In addition, it is not known whether cytosolic $\mathrm{Ca}^{2+}$ and mitochondrial dysfunction participates in CAP-induced TRPV1-mediated cell death. By using TRPV1-transfected HeLa cells, we investigated the underlying mechanisms involved in CAP-induced TRPV1-mediated cell death, the dependence of CAP dose, and the participation of mitochondrial dysfunction and cytosolic $\mathrm{Ca}^{2+}$ increase. Together, our results contribute to elucidate the pathophysiological steps that follow after TRPV1 stimulation with CAP. Low concentrations of CAP $(1 \mu \mathrm{M})$ induce cell death by a mechanism involving a TRPV1-mediated rapid and transient intracellular $\mathrm{Ca}^{2+}$ increase that stimulates plasma membrane depolarization, thereby compromising plasma membrane integrity and ultimately leading to cell death. Meanwhile, higher doses of CAP induce cell death via a TRPV1-independent mechanism, involving a slow and persistent intracellular $\mathrm{Ca}^{2+}$ increase that induces mitochondrial dysfunction, plasma membrane depolarization, plasma membrane loss of integrity, and ultimately, cell death.

Keywords: TRPV1, capsaicin, cell death, mitochondria, necrosis, calcium

\section{INTRODUCTION}

Transient receptor potential (TRP) channels belong to a polymodal family of ion channels that act as molecular transducers and integrators of a variety of environmental physicochemical stimuli, such as temperature, osmotic pressure, mechanical stress, and exogenous and endogenous ligands (Ramsey et al., 2006; Latorre et al., 2007, 2009). TRP channels play an essential role in multiple 
physiological and pathological cellular processes, such as proliferation, differentiation, and death progression (Shimizu et al., 2004; Shirakawa et al., 2008; Carrasco et al., 2018). Deregulated activation of TRP channels from the vanilloid (TRPV) family has been directly implicated in cell death (Macho et al., 1999; Amantini et al., 2009; Chen et al., 2012). TRPV1 has been detected in a variety of organs, such as the brain, testes, lungs, and heart. (Hayes et al., 2000; Randhawa and Jaggi, 2018). TRPV1 is widely expressed in dorsal root ganglion (DRG) and trigeminal neurons.

TRPV1 is activated by pain-inducing stimuli, including inflammatory endovanilloids, TNF- $\alpha$, TGF- $\beta$, heat $\left(37-42^{\circ} \mathrm{C}\right)$, acids ( $\mathrm{pH}<6.3$ ), and pungent exovanilloids, such as capsaicin (CAP) or resiniferatoxin (Caterina et al., 1997; Tominaga et al., 1998; Jordt et al., 2000; Olah et al., 2001, 2002; Latorre et al., 2007; Ma et al., 2011; Utreras et al., 2013; Rozas et al., 2016). TRPV1 activation by CAP is antagonized by the synthetic organic compound capsazepine (CPZ). At the cellular level, TRPV1 activation by high doses of CAP leads not only to necrotic processes with membrane bleb formation (Pecze et al., 2013; Wu et al., 2014) but also to apoptosis through caspase3 activation and mitochondrial membrane potential attenuation (Ziglioli et al., 2009; Sun et al., 2014; Çiğ and Nazıroğlu, 2015). However, CAP dose-response studies are lacking in order to understand whether CAP-induced cell death occurs preferentially via necrosis or apoptosis. Thus, the relationship between CAP concentration and CAP-induced TRPV1-mediated cell death is not completely understood.

Increased TRPV1 activity induces high levels of cytosolic $\mathrm{Ca}^{2+}$, generating mitochondrial membrane depolarization and decreased cell viability (Thomas et al., 2007). Furthermore, TRPV1 activation triggers apoptotic cell death in neuron-rich cultures from rat cerebral cortex via $\mathrm{Ca}^{2+}$ channels opening, allowing $\mathrm{Ca}^{2+}$ influx (Shirakawa et al., 2008). However, it is not known whether cytosolic $\mathrm{Ca}^{2+}$ and mitochondrial dysfunction participate in CAP-induced TRPV1-mediated cell death. Thus, we focused on investigating the underlying mechanisms involved in CAP-induced TRPV1-mediated cell death, the dependence of CAP dose, and the participation of mitochondrial dysfunction and cytosolic $\mathrm{Ca}^{2+}$ increase.

Using an analytical three-state model (O'Neill et al., 2011) to describe the mechanistic sequential progression from a state of health to a state of death, we found that TRPV1 stimulation with $10 \mu \mathrm{M}$ CAP significantly induces necrosis-like cell death characterized by extensive cell membrane damage but without affecting mitochondrial function. Interestingly, $100 \mu \mathrm{M}$ CAP induced a different pattern for cell death, characterized by mitochondrial dysfunction and is independent of TRPV1 activity, resembling an apoptosis-like death pattern. Furthermore, we found that TRPV1 stimulation with $1 \mu \mathrm{M}$ CAP induces a TRPV1-dependent fast and transient intracellular $\mathrm{Ca}^{2+}$ increase, while $10 \mu \mathrm{M}$ CAP induces a fast and persistent increase, which can be explained by the combination of two intracellular $\mathrm{Ca}^{2+}$ signals, a TRPV1-dependent fast and transient increase that is inhibited by CPZ, and a slow, persistent, and TRPV1independent rise of intracellular $\mathrm{Ca}^{2+}$. Finally, we demonstrated that $10 \mu \mathrm{M}$ CAP induces plasma membrane depolarization via an influx of $\mathrm{Ca}^{2+}$ and $\mathrm{Na}^{+}$from the extracellular space.

Our results show further mechanistical insights detailing how CAP induces TRPV1-dependent and independent cell death. Low concentrations of CAP $(1 \mu \mathrm{M})$ induce a fast and transient increase in intracellular $\mathrm{Ca}^{2+}$, which leads to plasma membrane depolarization, thereby compromising plasma membrane integrity, and ultimately driving cell physiology to a state of death but without mitochondrial dysfunction. Meanwhile, 10 and $100 \mu \mathrm{M}$ CAP induce a slow but persistent increase in intracellular $\mathrm{Ca}^{2+}$, which leads not only to plasma membrane depolarization but also to mitochondrial dysfunction, and ultimately cell death. Thus, CAP is shown to activate two independent pathways of $\mathrm{Ca}^{2+}$ homeostasis leading to cell death by necrosis or apoptosis.

\section{MATERIALS AND METHODS}

\section{Cell Culture}

HeLa cells were obtained from ATCC (Manassas, VA, United States). The culture medium used was Dulbecco's Modified Eagle Medium/F12 supplemented with $10 \%$ fetal bovine serum and $50 \mathrm{U} / \mathrm{ml}$ penicillin-streptomycin. Cells were incubated in a conventional incubator at $37^{\circ} \mathrm{C}$ and a $95 \%$ air $/ 5 \%$ $\mathrm{CO}_{2}$ atmosphere.

\section{HeLa Cells Stably Transfected With TRPV1 (st-TRPV1 HeLa Cells)}

HeLa cells were cultured at $70-80 \%$ confluence and then were transfected with pcDNA3.1 containing the full length of rat TRPV1 (GenBankTM accession no. NM031982) using Lipofectamine (ThermoFisher). Transfected cells were selected using Geneticin (Sigma-Aldrich, St. Louis, MO, United States, $800 \mathrm{mg} / \mathrm{mL}$ ) to generate a stable cell line encoding TRPV1. Stable TRPV1 expression was checked by RT-PCR and flow cytometry weekly (Supplementary Figure S1).

\section{Analysis of Quantitative Cell Death by Flow Cytometry}

HeLa cells were exposed to different experimental conditions in Dulbecco's Modified Eagle Medium /F12 supplemented with $1 \%$ bovine serum albumin instead of fetal bovine serum. Cellular death was determined as described in the literature (Darzynkiewicz et al., 1982) and analyzed according to a threestate model of cell death (O'Neill et al., 2011). Briefly, cell cultures were stained with $10 \mu \mathrm{M}$ rhodamine 123 (Rho123, Invitrogen, Carlsbad, CA, United States) to assess mitochondrial membrane potential, and propidium iodide (PI, $10 \mu \mathrm{g} / \mathrm{ml}$ (Sigma-Aldrich, St. Louis, MO, United States) to assess plasma membrane integrity. Both measures were analyzed by flow cytometry (FACScalibur, BD Biosciences, CA, United States). A minimum of 10,000 cells/sample were analyzed to evaluate mitochondrial function and membrane permeability. Fluorescence intensity analysis was performed using FlowJo software (Tree Star, Inc., Ashland, OR, United States). Cell state was operationally 
defined with the following first-order rate process: Alive $(A) \leftrightarrow$ Vulnerable $(V) \leftrightarrow$ Dead $(D)$. To determine probability for the $A$ state $\left(\mathrm{P}_{A}\right)$, data were normalized with respect to internal controls using the following equation: $P_{A}=X-C_{D} / C_{A}-C_{D}$, where $X$ corresponds to living cells in each experimental condition, $C_{D}$ corresponds to living cells in the presence of $10 \%$ ethanol to induce cell death, and $C_{A}$ corresponds to living cells without treatment.

\section{$\mathrm{Ca}^{2+}$ Imaging}

Cell cultures were loaded with Fura-2 AM (Molecular Probes, Eugene, OR, United States) for $30 \mathrm{~min}$ at room temperature in buffer solution [130 mM NaCl, $5.4 \mathrm{mM} \mathrm{KCl,} 2.5 \mathrm{mM} \mathrm{CaCl}$, $0.8 \mathrm{mM} \mathrm{MgCl}_{2}, 5.6 \mathrm{mM}$ glucose, $10 \mathrm{mM}$ HEPES, pH 7.4 (adjusted with Tris base)], rinsed, and allowed to equilibrate for 5-10 min. Next, HeLa cells were cultured on 12-mm glass cover slips in a recording chamber mounted on an epifluorescence Olympus IX81 microscope (Olympus, Japan) equipped with a multipleexcitation filter wheel. CAP-induced activity was recorded for a minimum recording time of $2 \mathrm{~s}$. Maximum resolution was obtained with a Plan Apo 40X 1.3 NA oil objective lens.

\section{Membrane Potential Measurement}

Cell cultures were equilibrated using $\operatorname{DiBAC}_{4}(3)$ [Molecular Probes, Eugene, OR, United States] as described previously (Kunz et al., 2006). This anionic fluorescent dye is distributed across the plasma membrane relative to the membrane potential following Nernst's equation (Olivero et al., 2008). $\operatorname{DiBAC}_{4}(3)$ (200 nM) was applied extracellularly for approximately $20 \mathrm{~min}$ to ensure dye distribution across the cell membrane. Changes in fluorescence intensity were monitored by sampling every $10 \mathrm{~s}$ for $30 \mathrm{~min}$ with a $515 \mathrm{~nm}$ excitation filter and an emission filter of at least $600 \mathrm{~nm}$. Fluorescence data were transformed to $\mathrm{mV}$ using a calibration curve from HeLa cells as described previously (Krasznai et al., 1995).

\section{RT-PCR}

Total RNA from parental HeLa cells and cells transfected with TRPV1 was extracted with TRIzol (Invitrogen, Carlsbad, CA, United States), and reverse transcription was performed to create a cDNA library using reverse transcriptase M-MLV (Invitrogen, Carlsbad, CA, United States). An equal amount of RNA was used as template in each reaction. The PCR reactions were performed using GoTaq Master Mix (Promega Corp., Madison, WI, United States) following the manufacturer's instructions.

\section{Immunodetection by Flow Cytometry}

HeLa cells were collected by trypsinization and fixed with $4 \%$ paraformaldehyde for $30 \mathrm{~min}$. Next, the cells were blocked and permeabilized using a PBS solution with 5\% bovine serum albumin (Merck KGaA, Darmstadt, Germany) and 2\% Tween-20 (Merck KGaA, Darmstadt, Germany) for $1 \mathrm{~h}$ and then incubated with an anti-TRPV1 antibody (Santa Cruz Biotechnology, Inc., United States, 1:200) in blocking solution overnight at $4^{\circ} \mathrm{C}$. After washing with PBS, the cells were incubated with antigoat biotinylated secondary antibody (Jackson ImmunoResearch,
United States, 1:500) for $1 \mathrm{~h}$ at $37^{\circ} \mathrm{C}$. The cells were washed with PBS and incubated in the dark with streptavidin-Alexa Fluor 488 (Jackson ImmunoResearch, United States, 1:200) for $1 \mathrm{~h}$ at $37^{\circ} \mathrm{C}$. The Alexa Fluor signal was measured with a 530/30 bandpass filter using an argon laser at $488 \mathrm{~nm}$ integrated into a FACScalibur flow cytometer (BD, Biosciences, CA, United States). Debris and duplets were excluded from the analysis, and a minimum of 10,000 cells were acquired in each experiment. Data were analyzed with FlowJo software (Tree Star, Inc., Ashland, OR, United States).

\section{Reagents}

Cyanide-4-(trifluoromethoxy)phenylhydrazone, FCCP, ionomycin, rodamine123, and PI were obtained from SigmaAldrich (St. Louis, MO, United States). CAP and CPZ were obtained from Tocris Bioscience (Bristol, United Kingdom). Buffers, ethanol, and salts were purchased from Merck (Darmstadt, Germany).

\section{Data Analysis}

All results are presented as the mean \pm SD from at least three independent assays for each experimental condition. Fisher's least significant difference test and an ANOVA test followed by the Bonferroni post hoc test were used to compare multiple groups using Statgraphics Plus 5.0 (GraphPad Software, Inc., San Diego, CA, United States). A $p$-value $<0.05$ was used to indicate statistical significance.

\section{RESULTS}

\section{TRPV1 Expression Increases CAP-Induced Cell Death}

The participation of TRPV1 expression and activity to sensitize cells to CAP-induced death was tested using a three-state cell death model. The three-state model [alive $(A)$, vulnerable $(V)$, and dead $(D)$ ] was established by means of flow cytometry dot plot analysis to determine cell death with or without mitochondrial involvement. Wild-type HeLa (wt-HeLa) cells were exposed to $10 \mu \mathrm{M}$ FCCP (Figure 1A) for 0, 30, and $120 \mathrm{~min}$, and $10 \%$ ethanol (Figure 1B) for 0,1 , and $12 \mathrm{~h}$. The three-state cell death model displayed a pronounced progression from $A$ $\left(\mathrm{PI}^{\text {low }} \mathrm{Rho} 123^{\text {hi }}\right.$ ), to $V$ ( $\mathrm{PI}^{\text {low }} \mathrm{Rho} 123^{\text {low }}$, or $\mathrm{PI}^{\text {hi }} \mathrm{Rho} 123^{\text {hi }}$ ), to $D$ (PI ${ }^{\text {hi }}$ Rho123 ${ }^{\text {low }}$; Figures 1A,B). The induction of an intermediate $\mathrm{PI}^{\text {low }}$ Rho123 $3^{\text {low }} V$-phenotype indicates loss of mitochondrial membrane potential without plasma membrane disruption (Figure 1A), while PI ${ }^{\text {hi }}$ Rho $123^{\text {hi }} V$-phenotype indicates plasma membrane disruption, but without loss of mitochondrial membrane potential (Figure 1B). Cell phenotype did not remain constant, and the proportion of cells in the three states varied over time. Cells achieved a full phenotype shift toward the $D$ state after $3 \mathrm{~h}$ of exposure to FCCP (Figure 1C) and after $9 \mathrm{~h}$ of exposure to $10 \%$ ethanol (Figure 1D). Cells reached the intermediate $V$ state at approximately $1 \mathrm{~h}$ of exposure to either FCCP or $10 \%$ ethanol, and $\mathrm{P}_{A}$ was greater for cells exposed to FCCP than to $10 \%$ ethanol. Therefore, HeLa cell physiology 


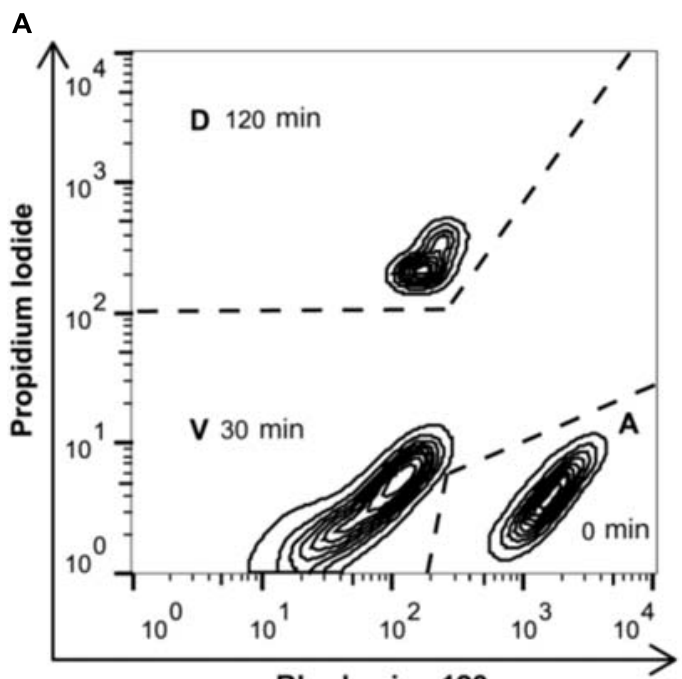

Rhodamine 123

C

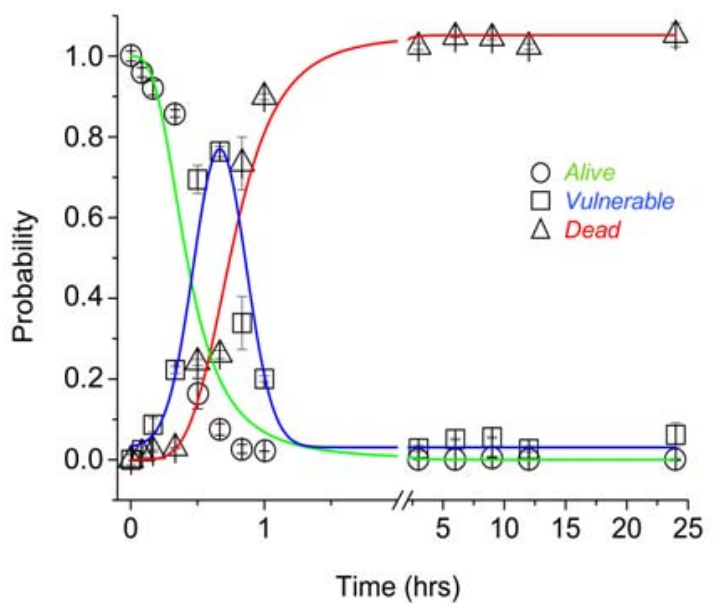

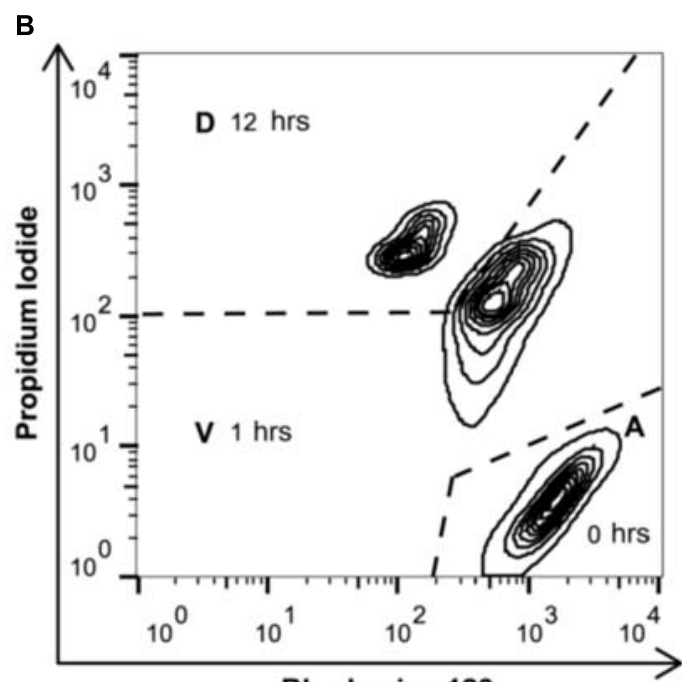

Rhodamine 123

D

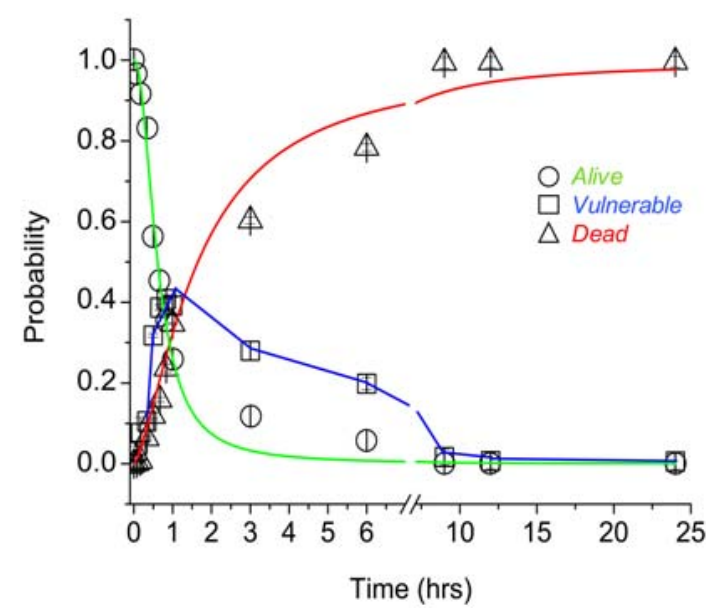

FIGURE 1 | Three-state model of cell death. Representative flow cytometry dot plot output depicting 24-h exposure of non-transfected wt-HeLa cell phenotype exposed to $10 \mu \mathrm{M}$ FCCP (A) and 10\% ethanol (B). Cell death progression was evaluated using PI (to assess plasma membrane integrity) and Rho123 (to assess mitochondrial membrane potential). Cell state progression is symbolized as $A$ (alive), $V$ (vulnerable), and $D$ (dead). Replicate experiments [from (A,B)] were performed for different times between 0 and $24 \mathrm{~h}$, and were normalized against $P_{A}=1$ to determine the probability for cell state [(C,D) respectively]. Data are shown as mean $\pm \operatorname{SEM}(n=9)$.

appeared more sensitive to mitochondrial dysfunction than to plasma membrane disruption, as shown with $\mathrm{P}_{A}$ progression curves.

Once the three-state cell death model was established, we investigated the effect of TRPV1 expression in HeLa cells stably transfected with TRPV1 (st-TRPV1). Transfection efficiency in generating the st-TRPV1 was confirmed at the mRNA level by RT-PCR and at the protein level by flow cytometry (Supplementary Figure S1). Flow cytometry analysis revealed that in the absence of CAP, wt-HeLa cells predominantly exhibited a phenotype consistent with the $A$ state $\left(\mathrm{PI}^{\text {low }} \mathrm{Rho} 123^{\text {hi }}\right.$ ), without plasma membrane disruption or mitochondrial dysfunction (Figure 2, upper-left panel). Similar results were observed for st-TRPV1 HeLa cells in the absence (Figure 2, upper-middle panel) or presence of CPZ (Figure 2, upper-right panel), and in wt-HeLa cells exposed to $10 \mu \mathrm{M}$ CAP (Figure 2, middleleft panel). However, st-TRPV1 HeLa cells exposed to $10 \mu \mathrm{M}$ CAP showed a phenotype $\left(\mathrm{PI}^{\text {low-hi }}\right.$ Rho123 ${ }^{\text {hi }}$ ) predominantly indicative of plasma membrane loss of integrity without mitochondrial dysfunction (Figure 2, middle-middle panel), a phenotype that resembles a necrosis-like cell death. Interestingly, st-TRPV1 HeLa cells pre-treated with $10 \mu \mathrm{M}$ CPZ and then treated with $10 \mu \mathrm{M}$ CAP exhibited a cell phenotype consistent with the $A$ state (Figure 2, middle-right panel), suggesting that $10 \mu \mathrm{M} \mathrm{CPZ}$ is able to prevent cell death. Wt-HeLa cells exposed to $100 \mu \mathrm{M}$ CAP showed a phenotype (PI ${ }^{\text {hi }}$ Rho $123^{\text {low }}$ ) predominantly indicative of plasma membrane loss of integrity and severe mitochondrial dysfunction (Figure 2, lower-left panel). Similarly, st-TRPV1 HeLa cells exposed to $100 \mu \mathrm{M}$ CAP exhibited a phenotype (PI ${ }^{\text {hi }}$ Rho $123^{\text {mid }}$ ) consistent with the $D$ 


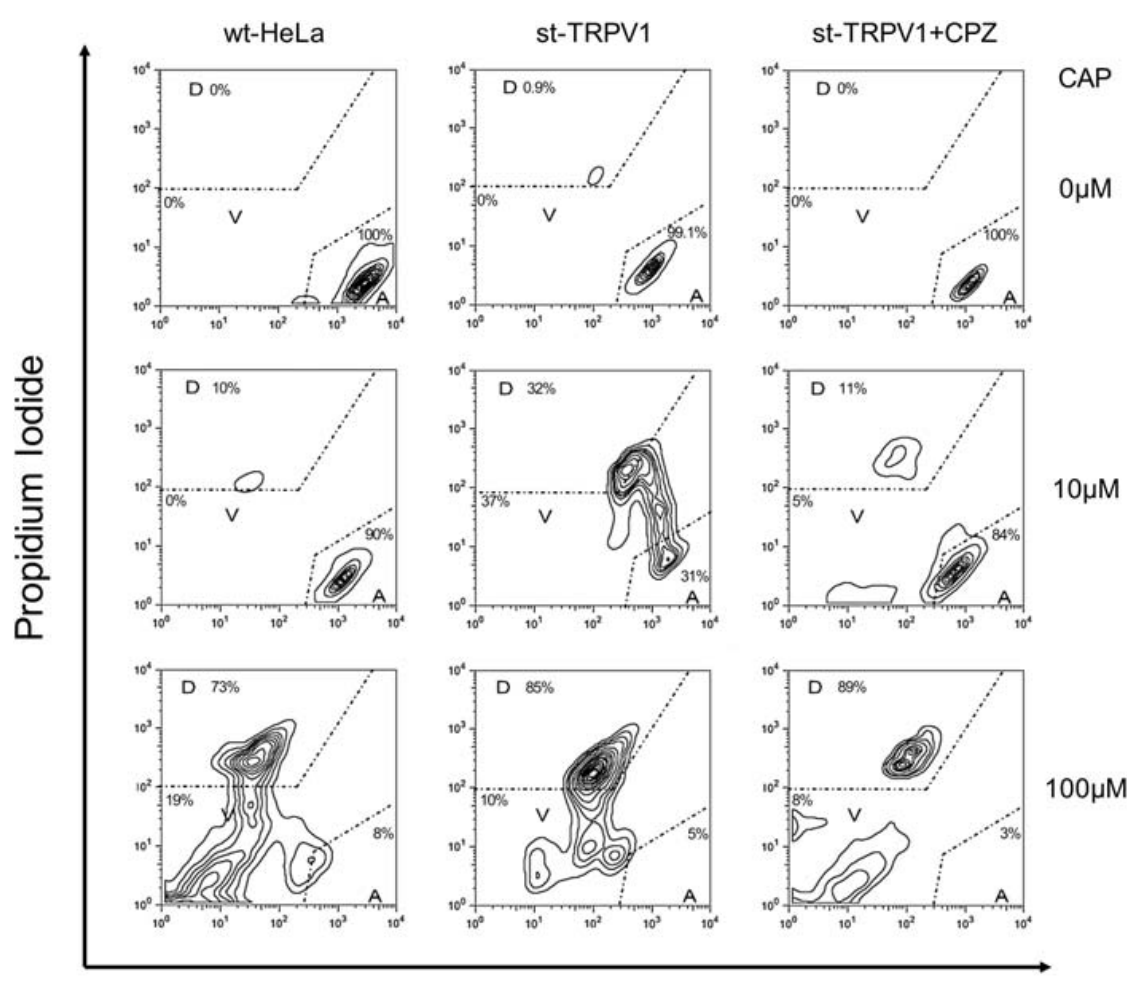

Rhodamine 123

FIGURE 2 | TRPV1 expression increases CAP-induced cell death. Representative flow cytometry dot plot output and quantification depicting wt-HeLa cells and st-TRPV1 HeLa cells exposed to 0, 10, and $100 \mu \mathrm{M}$ CAP for $24 \mathrm{~h}$ in the presence or absence of $10 \mu \mathrm{M} \mathrm{CPZ}$. Cell death progression was evaluated using PI (to assess plasma membrane integrity) and Rho123 (to assess mitochondrial membrane potential). Cell state progression is symbolized as $A$ (alive), $V$ (vulnerable), and $D$ (dead). Data are shown as mean $\pm \operatorname{SEM}(n=6)$.
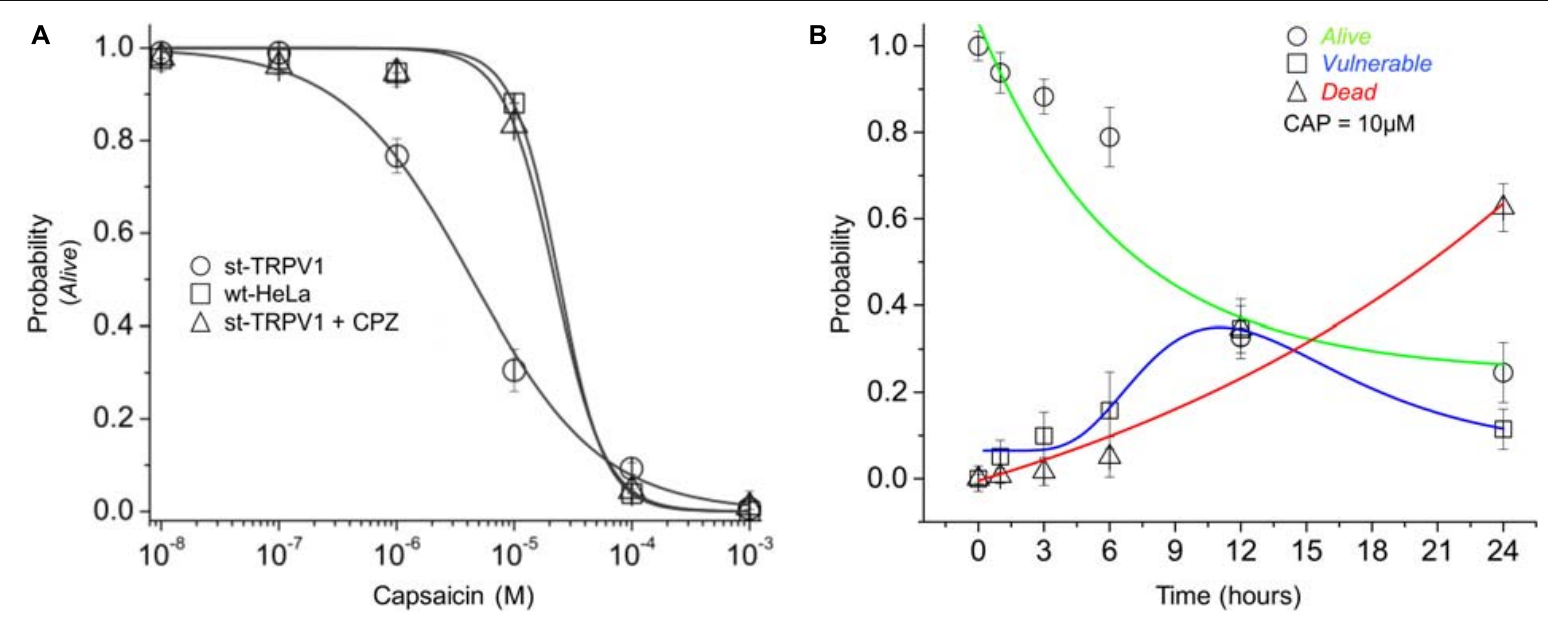

FIGURE 3 | Dose- and time-response of CAP-induced cell death. (A) Probability of cell state $A\left(P_{A}\right)$ of wt-HeLa cells and st-TRPV1 HeLa cells in the presence or absence of $10 \mu \mathrm{M} \mathrm{CPZ}$ exposed to several concentration of CAP $\left(1 \cdot 10^{-3}\right.$ to $\left.1 \cdot 10^{-8} \mathrm{M}\right)$ for $24 \mathrm{~h}$. (B) Probability of cell state progression of st-TRPV1 HeLa cells exposed to $10 \mu \mathrm{M}$ CAP for $0,1,3,6,12$, and $24 \mathrm{~h}$. Data are shown as mean $\pm \operatorname{SEM}(n=5)$. ${ }^{*} p<0.01$.

state with both plasma membrane disruption and mitochondrial failure (Figure 2, lower-middle panel), indicative of an apoptosislike cell death. Notably, pre-treatment with $10 \mu \mathrm{M} \mathrm{CPZ}$ of st-TRPV1 HeLa cells exposed to $100 \mu \mathrm{M}$ CAP was not effective protecting the cells from CAP challenge, showing a phenotype (PI ${ }^{\text {hi }}$ Rho123 ${ }^{\mathrm{mid}}$ ) consistent with the $D$ state (Figure 2, lowerright panel). Thus, these results indicate that $10 \mu \mathrm{M}$ CAP induces TRPV1-mediated cell death without affecting mitochondrial 

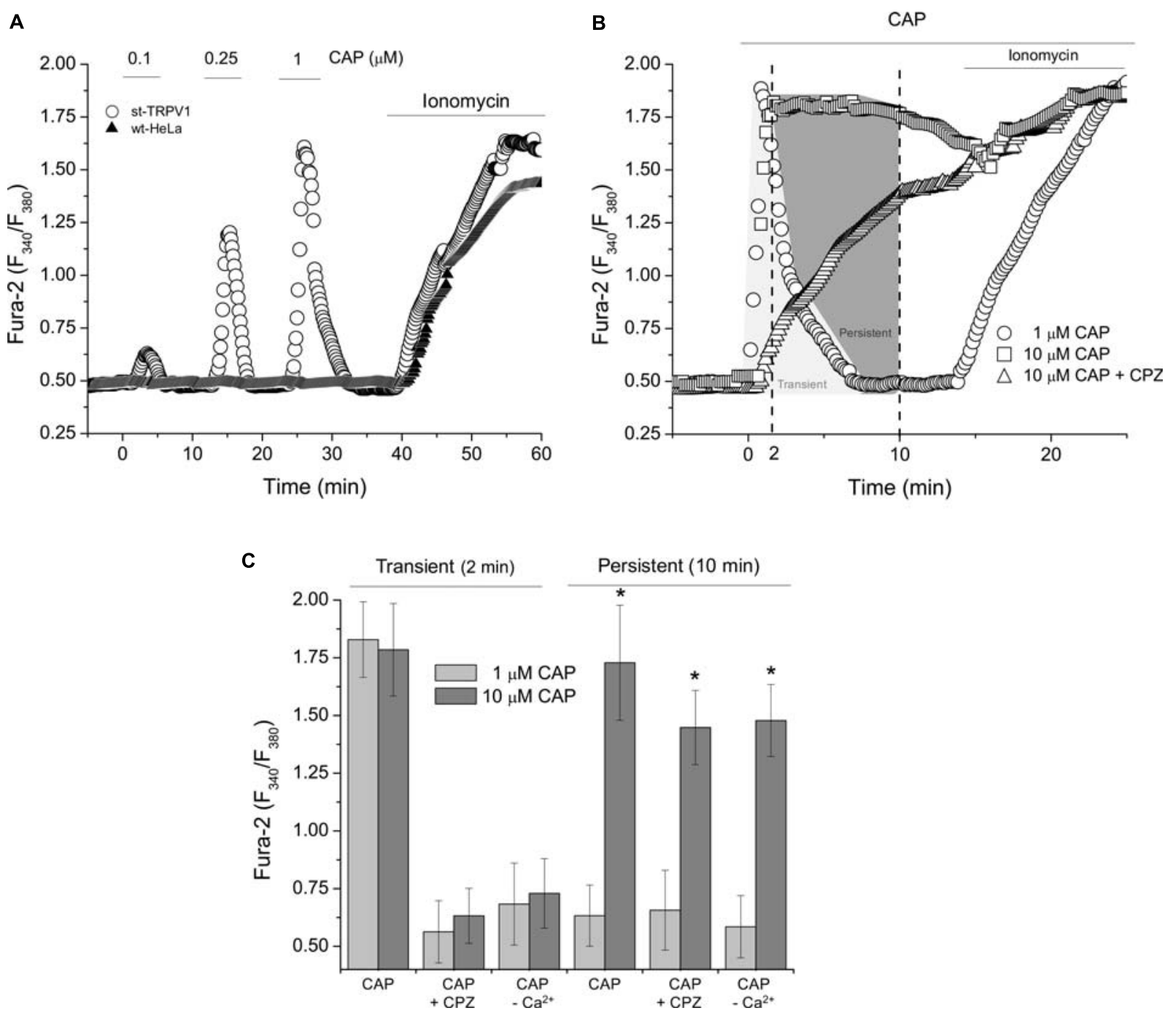

FIGURE 4 | TRPV1 expression increases intracellular calcium level in response to CAP. (A) Dose-response curve of ratiometric assay recordings for [Ca ${ }^{2+}{ }_{1}$ in wt-HeLa cells and st-TRPV1 HeLa cells exposed to $0.1,0.25$, and $1 \mu \mathrm{M}$ CAP for $60 \mathrm{~min}$. Representative experiments from five independent experiments. (B) Dose-response curve of ratiometric assay recordings for $\left[\mathrm{Ca}^{2+}\right]_{І}$ in st-TRPV1 HeLa cells exposed to 1 and $10 \mu \mathrm{M}$ CAP in the presence or absence of $10 \mu \mathrm{M}$ CPZ for 20 min. Representative experiments from five independent experiments. $10 \mu \mathrm{M}$ ionomycin was added at the end of experiments (A) and (B) as positive control. (C) Cross-sectional ratiometric [Ca $\left.{ }^{2+}\right]_{1}$ in st-TRPV1 HeLa cells exposed to 1 and $10 \mu \mathrm{M}$ CAP at times 2 and 10 min after CAP exposition, in the presence or absence of $10 \mu \mathrm{M} \mathrm{CPZ}$ or $\mathrm{Ca}^{2+}$-free condition. Data are shown as mean $\pm \operatorname{SEM}(n=15) .{ }^{*} p<0.01$.

physiology, while $100 \mu \mathrm{M}$ CAP induces cell death in a TRPV1-independent fashion, characterized by mitochondrial potential dysfunction and plasma membrane disruption. Phasecontrast images highlighting the main morphological features of each condition for wt-HeLa and st-TRPV1 HeLa cells were documented and summarized in Supplementary Figure S2.

To investigate the dose-response effect of CAP, st-TRPV1 HeLa cells were exposed to increasing doses of CAP for $24 \mathrm{~h}$. The results showed that CAP has a sensitizing effect over st-TRPV1 HeLa cells, decreasing the $\mathrm{P}_{A}$ when compared to wt-HeLa cells $\left(\mathrm{P}_{\mathrm{A} 50}\right.$ from $\sim 3.5 \cdot 10^{-5}$ to $\left.\sim 4.5 \cdot 10^{-6} \mu \mathrm{M} \mathrm{CAP}\right)$. Interestingly, addition of the TRPV1 competitive antagonist CPZ (which blocks CAP-induced $\mathrm{Ca}^{2+}$ uptake through TRPV1) to CAP treated stTRPV1 HeLa cells completely overturned the original sensitizing effect of CAP, contributing to cell resistance to a level close to wt-HeLa cells response (Figure 3A). As a next step, we studied the time-response (0-24 h) of st-TRPV1 cells exposed to $10 \mu \mathrm{M}$ CAP. The proportion of st-TRPV1 cells in the $V$ state was maximal after $12 \mathrm{~h}$ of exposure to $10 \mu \mathrm{M}$ CAP. The $A$ state in st-TRPV1 cells reached $50 \%$ after $\sim 7 \mathrm{~h}$ of CAP exposure, while the $D$ state increased steadily (Figure 3B). These results indicate that the CAP-induced cell-state transition is mediated by TRPV1.

\section{TRPV1 Expression Increases Intracellular Calcium Level in Response to CAP}

To investigate the intracellular effect of CAP-mediated TRPV1 stimulation, we measured $\mathrm{Ca}^{2+}$ dynamics with ratiometric 


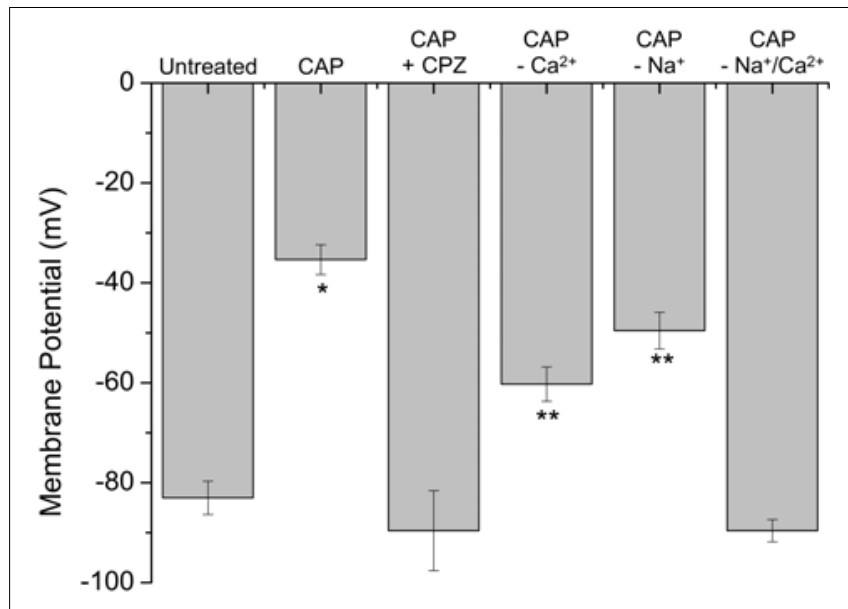

FIGURE 5 | TRPV1 expression induces plasma membrane depolarization in response to CAP. Membrane potential measured by the change in $\mathrm{DiBAC}_{4}(3)$ fluorescence intensity in st-TRPV1 HeLa cells exposed to $10 \mu \mathrm{M}$ CAP for $30 \mathrm{~min}$, in the presence or absence of $10 \mu \mathrm{M} \mathrm{CPZ}, \mathrm{Ca}^{2+}$-free condition, or $\mathrm{Na}^{+}$-free condition. Data are shown as mean \pm SEM $(n=5) .{ }^{*} p<0.01$ and $* * p<0.05$.

assays. Measurements of intracellular $\mathrm{Ca}^{2+}$ levels showed that wt-HeLa cells were irresponsive to CAP stimulation. However, st-TRPV1 HeLa cells were able to respond to CAP treatment exhibiting transient and dose-dependent increases in intracellular calcium concentration $\left(\left[\mathrm{Ca}^{2+}\right]_{\text {I }}\right.$; Figure 4A). Addition of $1 \mu \mathrm{M}$ CAP to st-TRPV1 HeLa cells showed a fast and transient rise in $\left[\mathrm{Ca}^{2+}\right]_{\mathrm{I}}$ after $2 \mathrm{~min}$ of exposure to CAP reaching basal levels shortly before $10 \mathrm{~min}$ (Figure 4B). However, stTRPV1 HeLa cells treated with $10 \mu \mathrm{M}$ CAP showed a fast and persistent increase in $\left[\mathrm{Ca}^{2+}\right]_{\mathrm{I}}$, without return to basal levels after $10 \mathrm{~min}$. Interestingly, when the latter cells were simultaneously exposed to $10 \mu \mathrm{M} \mathrm{CPZ}$, the fast increase in $\left[\mathrm{Ca}^{2+}\right]_{\mathrm{I}}$ was prevented, showing a slow and constant increase in $\left[\mathrm{Ca}^{2+}\right]_{\mathrm{I}}$ reaching levels similar to those observed in the absence of CPZ (Figure 4B). Thus, $10 \mu \mathrm{M}$ CAP elicits two $\mathrm{Ca}^{2+}$ signals combined, a TRPV1-dependent fast and transient increase and another slow and persistent $\mathrm{Ca}^{2+}$ increase, without participation of TRPV1. As a positive control, cells were responsive to ionomycin (Figures 4A,B).

Whether the increase in intracellular $\mathrm{Ca}^{2+}$ levels was mediated by TRPV1, we were prompted to determine the participation of extracellular $\mathrm{Ca}^{2+}$ on the CAP-induced increase on intracellular $\mathrm{Ca}^{2+}$ levels. Figure $4 \mathrm{C}$ depicts both the transient and the persistent increases in $\left[\mathrm{Ca}^{2+}\right]_{\mathrm{I}}$ from experiments as shown in Figure 4B. St-TRPV1 HeLa cells exposed to $1 \mu \mathrm{M}$ CAP showed a transient, but not persistent increase in $\left[\mathrm{Ca}^{2+}\right]_{\mathrm{I}}$, while cells exposed to $10 \mu \mathrm{M}$ CAP showed a persistent increase in $\left[\mathrm{Ca}^{2+}\right]_{\mathrm{I}}$. The addition of $10 \mu \mathrm{M} \mathrm{CPZ}$ prevented both the transient increase in $\left[\mathrm{Ca}^{2+}\right]_{\mathrm{I}}$ independent of CAP concentration, but $\mathrm{CPZ}$ failed into inhibit the persistent increase in $\left[\mathrm{Ca}^{2+}\right]_{\mathrm{I}}$ when $10 \mu \mathrm{M}$ CAP was present. Interestingly, after removal of extracellular $\mathrm{Ca}^{2+}$, transient $\mathrm{Ca}^{2+}$ increases were prevented for both 1 and $10 \mu \mathrm{M}$ CAP treatments, suggesting that
CAP-induced transient increases in $\left[\mathrm{Ca}^{2+}\right]_{\mathrm{I}}$ are dependent on extracellular $\mathrm{Ca}^{2+}$ and considering that it is CPZ-sensitive, this influx is mediated TRPV1. However, after extracellular $\mathrm{Ca}^{2+}$ depletion, $10 \mu \mathrm{M}$ CAP was still able to stimulate an increase in $\left[\mathrm{Ca}^{2+}\right]_{\mathrm{I}}$, potentially due to a secondary mechanism involving $\mathrm{Ca}^{2+}$ mobilization from an intracellular storage compartment (Figure 4C).

\section{TRPV1 Expression Induces Plasma Membrane Depolarization in Response to CAP}

Considering that stimulation of st-TRPV1 with CAP generated a fast increase in $\left[\mathrm{Ca}^{2+}\right]_{\mathrm{I}}$ (Figure 4B) and that CAP induced a disruption in membrane integrity but not mitochondrial function (Figure 2, middle panel), we determined whether CAP challenge could depolarize plasma membrane potential. St-TRPV1 HeLa cells exposed to $10 \mu \mathrm{M}$ CAP for $30 \mathrm{~min}$ increased the fluorescence of the membrane potential fluorescent indicator $\mathrm{DIBAC}_{4}(3)$, suggesting that exposure to $10 \mu \mathrm{M}$ CAP induced a significant depolarization of the plasma membrane from approximately $-80 \mathrm{mV}$ in non-treated st-TRPV 1 HeLa cells to $-35 \mathrm{mV}$ (Figure 5). Interestingly, selective inactivation of TRPV1 with $10 \mu \mathrm{M}$ CPZ prevented the CAP-induced plasma membrane depolarization, suggesting that TRPV1 participates in plasma membrane depolarization induced by CAP.

To investigate whether CAP-induced plasma membrane depolarization requires external $\mathrm{Ca}^{2+}$, st-TRPV1 HeLa cells were exposed to $10 \mu \mathrm{M}$ CAP in the absence of extracellular $\mathrm{Ca}^{2+}$. These results showed that in the absence of external $\mathrm{Ca}^{2+}$, CAP-induced plasma membrane depolarization was significantly decreased. Often, intracellular $\mathrm{Ca}^{2+}$ increases are followed by increases in intracellular $\mathrm{Na}^{+}$, which severely contribute to plasma membrane depolarization (Figure 5; Castro et al., 2006). To test this possibility, st-TRPV1 HeLa cells were exposed to $10 \mu \mathrm{M}$ CAP in the presence of a culture medium depleted of $\mathrm{Na}^{+}$by means of replacing $\mathrm{Na}^{+}$ with the non-permeable cation $\mathrm{NMDG}^{+}$, thereby maintaining osmolarity and tonicity constant. These results showed that in the absence of external $\mathrm{Na}^{+}$, the CAP-induced plasma membrane depolarization was significantly decreased. Remarkably, CAPinduced plasma membrane depolarization was completely prevented when both $\mathrm{Ca}^{2+}$ and $\mathrm{Na}^{+}$were absent from the extracellular medium (Figure 5). Thus, CAP-induced plasma membrane depolarization appears to be an additive effect of $\mathrm{Ca}^{2+}$ and $\mathrm{Na}^{+}$influxes. $\mathrm{DIBAC}_{4}(3)$ efficiency to measure plasma membrane potential was validated using valinomycin and gramicidin (Supplementary Figure S3).

\section{DISCUSSION}

This study highlights how TRPV1 activity is required to induce cell death. Here, we suggest that TRPV1 stimulation with CAP induces necrotic-like cell death without mitochondrial dysfunction, in a mechanism that involves a fast and transient increase in intracellular $\mathrm{Ca}^{2+}$, leading to plasma membrane depolarization and a loss of plasma membrane integrity. 
Interestingly, $100 \mu \mathrm{M}$ CAP generates mitochondrial dysfunction and TRPV1-independent apoptotic-like cell death.

TRPV1 expression exhibits dose-dependent cytotoxic effects, including mitochondrial store-dependent $\mathrm{Ca}^{2+}$ overload (Lam et al., 2007; Hu et al., 2008; Davies et al., 2010), membrane bleb formation (Pecze et al., 2013; Wu et al., 2014), pyknotic nuclear fragmentation, cytochrome $c$ release from mitochondria, caspase-3 activation (Davies et al., 2010), and cell viability (Maeno et al., 2000; Bortner and Cidlowski, 2002; Stutzin and Hoffmann, 2006; Lam et al., 2007; Panayiotidis et al., 2010). Indeed, TRPV1 activation promises therapeutic use by rapidly and selectively inducing necrosis in TRPV1expressing nociceptive neurons (Olah et al., 2001), thereby inducing analgesia most likely via $\mathrm{Ca}^{2+}$-mediated cytotoxicity (Marsch et al., 2007; Gunthorpe and Chizh, 2009; Lambert, 2009). Furthermore, the analgesic effects of CAP - via TRPV1 activation - are associated with the inhibition of hyperpolarization-activated cation currents $\left(I_{\mathrm{h}}\right)$, which depend on intracellular $\mathrm{Ca}^{2+}$ mobilization (Kwak, 2012). Optimal mitochondrial physiology maintains a low cytoplasmic $\mathrm{Ca}^{2+}$ concentration through mitochondrial refilling and/or ATPdependent $\mathrm{Ca}^{2+}$ compartmentalization processes (Varikmaa et al., 2013). Thus, CAP can induce sustained $\mathrm{Ca}^{2+}$ increases, likely via the release of $\mathrm{Ca}^{2+}$ stores caused by mitochondrial failure or mitochondrial fission.

Stable TRPV1 expression and stimulation induces membrane depolarization through an increase in intracellular $\mathrm{Ca}^{2+}$. Although transient increases in $\mathrm{Ca}^{2+}$ did not induce a change in cell state, heavy stimulation of TRPV1 with $100 \mu \mathrm{M}$ CAP was able to trigger a toxic $\mathrm{Ca}^{2+}$ overload, likely due to intracellular mitochondrial $\mathrm{Ca}^{2+}$ release. Mitochondrial $\mathrm{Ca}^{2+}$ exchange with the cytoplasm has been previously reported (Malli et al., 2003) and $\mathrm{Ca}^{2+}$ uptake has been proposed to generate microdomains of low $\mathrm{Ca}^{2+}$ concentrations across the cytoplasm (Youle and van der Bliek, 2012). In fact, mitochondrial function has been found to be finely regulated by $\mathrm{Ca}^{2+}$-dependent ion channels, capable of regulating the electrochemical gradients required to mobilize $\mathrm{Ca}^{2+}$ into intracellular stores (Malli et al., 2003). Thus, the loss of membrane potential is likely induced by the activation of TRPV1 and a massive $\mathrm{Ca}^{2+}$ influx, leading to CAP-induced cell death.

Endogenous TRPV1 expression in many tissues, such as the brain, heart, skin, and testis, has been reported to play a role in cell death (Kunert-Keil et al., 2006; Marsch et al., 2007). For example, TRPV1-mediated neurotoxicity has been reported in a large spectrum of assays involving primary cultures, as well as tissues, organs, and in toto experiments

\section{REFERENCES}

Amantini, C., Ballarini, P., Caprodossi, S., Nabissi, M., Morelli, M. B., Lucciarini, R., et al. (2009). Triggering of transient receptor potential vanilloid type 1 (TRPV1) by capsaicin induces Fas/CD95-mediated apoptosis of urothelial cancer cells in an ATM-dependent manner. Carcinogenesis 30, 1320-1329. doi: 10.1093/carcin/bgp 138

Bortner, C. D., and Cidlowski, J. A. (2002). Apoptotic volume decrease and the incredible shrinking cell. Cell Death Differ. 9, 1307-1310. doi: 10.1038/sj.cdd. 4401126
(Shin et al., 2003; Cernak et al., 2004; Shirakawa et al., 2008). In fact, direct application of CAP to the substantia nigra can induce the depletion of dopaminergic neurons (Kim et al., 2005). Moreover, deregulated TRPV1 activation by endogenous agonists induces the loss of hippocampal neurons and an impairment of cognitive functions (Cernak et al., 2004). These findings, along with observations by other authors, raise the possibility that TRPV1 receptors may be inducing cell death via oxidative stress (Macho et al., 1999; Movsesyan et al., 2004; Lam et al., 2007; Shirakawa et al., 2008), mitochondrial disruption (Macho et al., 1999; Shin et al., 2003), and intracellular $\mathrm{Ca}^{2+}$ overload (Chard et al., 1995; Cernak et al., 2004; Lam et al., 2007; Shirakawa et al., 2008). Nevertheless, this conjecture falls beyond the scope of this work and warrants further investigation in neuronal cells.

Taken together, the results shown in this study suggest that the expression and specific activation of TRPV1 can induce TRPV1dependent $\mathrm{Ca}^{2+}$ signaling modifications that lead to a plasma membrane potential depolarization contributing to cell death.

\section{AUTHOR CONTRIBUTIONS}

RR-B, CC, SG, BR, CL, IM, CE, FS, and PO critically revised and edited this manuscript. RR-B, FS, and PO participated in the research design. RR-B, CC, BR, CL, IM, and PO conducted the experiments and performed data analyses. R-RB, SG, FS, and PO contributed to the figure design. RR-B, SG, IM, CE, FS, and PO wrote the paper.

\section{FUNDING}

This work was supported by research grants from Fondo Nacional de Desarrollo Científico y Tecnológico - FONDECYT 1140693, 11100047 (PO), 1111039 (IM), 11170840 (CE), and 1161288 (FS), Millennium Institute on Immunology and Immunotherapy P09-016-F (FS), and Comisión Nacional de Investigación Científica y Tecnológica (CONICYT) Ph.D. scholarship 21171566 (SG) and UNAB DI-741-15/N (FS).

\section{SUPPLEMENTARY MATERIAL}

The Supplementary Material for this article can be found online at: https://www.frontiersin.org/articles/10.3389/fphys. 2018.00682/full\#supplementary-material

Carrasco, C., Naziroĝlu, M., Rodriìguez, A., and Pariente, J. (2018). Neuropathic pain: delving into the oxidative origin and the possible implication of transient receptor potential channels. Front. Physiol. 9:95. doi: 10.3389/fphys.2018.00095

Castro, J., Ruminot, I., Porras, O. H., Flores, C. M., Hermosilla, T., Verdugo, E., et al. (2006). ATP steal between cation pumps: a mechanism linking $\mathrm{Na}^{+}$ influx to the onset of necrotic $\mathrm{Ca}^{2+}$ overload. Cell Death Differ. 13, 1675-1685. doi: $10.1038 /$ sj.cdd.4401852

Caterina, M. J., Schumacher, M. A., Tominaga, M., Rosen, T. A., Levine, J. D., and Julius, D. (1997). The capsaicin receptor: a heat-activated ion channel in the pain pathway. Nature 389, 816-824. doi: 10.1038/39807 
Cernak, I., Vink, R., Natale, J., Stoica, B., Lea, P. M., Movsesyan, V., et al. (2004). The "dark side" of endocannabinoids: a neurotoxic role for anandamide. J. Cereb. Blood Flow Metab. 24, 564-578. doi: 10.1097/00004647-20040500000011

Chard, P. S., Bleakman, D., Savidge, J. R., and Miller, R. J. (1995). Capsaicininduced neurotoxicity in cultured dorsal root ganglion neurons: involvement of calcium-activated proteases. Neuroscience 65, 1099-1108. doi: 10.1016/03064522(94)00548-J

Chen, D., Yang, Z., Wang, Y., Zhu, G., and Wang, X. (2012). Capsaicin induces cycle arrest by inhibiting cyclin-dependent-kinase in bladder carcinoma cells. Int. J. Urol. 19, 662-668. doi: 10.1111/j.1442-2042.2012.02981.x

Çiğ, B., and Nazıroğlu, M. (2015). Investigation of the effects of distance from sources on apoptosis, oxidative stress and cytosolic calcium accumulation via TRPV1 channels induced by mobile phones and Wi-Fi in breast cancer cells. Biochim. Biophys. Acta 1848, 2756-2765. doi: 10.1016/j.bbamem.2015.02.013

Darzynkiewicz, Z., Traganos, F., Staiano-Coico, L., Kapuscinski, J., and Melamed, M. R. (1982). Interaction of rhodamine 123 with living cells studied by flow cytometry. Cancer Res. 42, 799-806.

Davies, J. W., Hainsworth, A. H., Guerin, C. J., and Lambert, D. G. (2010). Pharmacology of capsaicin-, anandamide-, and $\mathrm{N}$-arachidonoyl-dopamineevoked cell death in a homogeneous transient receptor potential vanilloid subtype 1 receptor population. Br. J. Anaesth. 104, 596-602. doi: 10.1093/bja/ aeq067

Gunthorpe, M. J., and Chizh, B. A. (2009). Clinical development of TRPV1 antagonists: targeting a pivotal point in the pain pathway. Drug Discov. Today 14, 56-67. doi: 10.1016/j.drudis.2008.11.005

Hayes, P., Meadows, H. J., Gunthorpe, M. J., Harries, M. H., Duckworth, D. M., Cairns, W., et al. (2000). Cloning and functional expression of a human orthologue of rat vanilloid receptor-1. Pain 88, 205-215. doi: 10.1016/S03043959(00)00353-5

Hu, F., Sun, W. W., Zhao, X. T., Cui, Z. J., and Yang, W. X. (2008). TRPV1 mediates cell death in rat synovial fibroblasts through calcium entry-dependent ROS production and mitochondrial depolarization. Biochem. Biophys. Res. Commun. 369, 989-993. doi: 10.1016/j.bbrc.2008.02.155

Jordt, S. E., Tominaga, M., and Julius, D. (2000). Acid potentiation of the capsaicin receptor determined by a key extracellular site. Proc. Natl. Acad. Sci. U.S.A. 97, 8134-8139. doi: 10.1073/pnas.100129497

Kim, S. R., Lee, D. Y., Chung, E. S., Oh, U. T., Kim, S. U., and Jin, B. K. (2005). Transient receptor potential vanilloid subtype 1 mediates cell death of mesencephalic dopaminergic neurons in vivo and in vitro. J. Neurosci. 25, 662-671. doi: 10.1523/jneurosci.4166-04.2005

Krasznai, Z., Márián, T., Balkay, L., Emri, M., and Trón, L. (1995). Flow cytometric determination of absolute membrane potential of cells. J. Photochem. Photobiol. B Biol. 28, 93-99. doi: 10.1016/1011-1344(94)07099-A

Kunert-Keil, C., Bisping, F., Krüger, J., and Brinkmeier, H. (2006). Tissue-specific expression of TRP channel genes in the mouse and its variation in three different mouse strains. BMC Genomics 7:159. doi: 10.1186/1471-2164-7-159

Kunz, L., Richter, J. S., and Mayerhofer, A. (2006). The adenosine 5'-triphosphatesensitive potassium channel in endocrine cells of the human ovary: role in membrane potential generation and steroidogenesis. J. Clin. Endocrinol. Metab. 91, 1950-1955. doi: 10.1210/jc.2005-2269

Kwak, J. (2012). Capsaicin blocks the hyperpolarization-activated inward currents via TRPV1 in the rat dorsal root ganglion neurons. Exp. Neurobiol. 21, 75-82. doi: $10.5607 /$ en.2012.21.2.75

Lam, P. M., Hainsworth, A. H., Smith, G. D., Owen, D. E., Davies, J., and Lambert, D. G. (2007). Activation of recombinant human TRPV1 receptors expressed in SH-SY5Y human neuroblastoma cells increases $\left[\mathrm{Ca}^{2+}\right](\mathrm{i})$, initiates neurotransmitter release and promotes delayed cell death. J. Neurochem. 102, 801-811. doi: 10.1111/j.1471-4159.2007.04569.x

Lambert, D. G. (2009). Capsaicin receptor antagonists: a promising new addition to the pain clinic. Br. J. Anaesth. 102, 153-155. doi: 10.1093/bja/ae n354

Latorre, R., Brauchi, S., Orta, G., Zaelzer, C., and Vargas, G. (2007). ThermoTRP channels as modular proteins with allosteric gating. Cell Calcium 42, 427-438. doi: 10.1016/j.ceca.2007.04.004

Latorre, R., Zaelzer, C., and Brauchi, S. (2009). Structure-functional intimacies of transient receptor potential channels. Q. Rev. Biophys. 42, 201-246. doi: $10.1017 /$ S0033583509990072
Ma, L., Zhong, J., Zhao, Z., Luo, Z., Ma, S., Sun, J., et al. (2011). Activation of TRPV1 reduces vascular lipid accumulation and attenuates atherosclerosis. Cardiovasc. Res. 92, 504-513. doi: 10.1093/cvr/cvr245

Macho, A., Calzado, M. A., Muñoz-Blanco, J., Gómez-Díaz, C., Gajate, C., Mollinedo, F., et al. (1999). Selective induction of apoptosis by capsaicin in transformed cells: the role of reactive oxygen species and calcium. Cell Death Differ. 6, 155-165. doi: 10.1038/sj.cdd.4400465

Maeno, E., Ishizaki, Y., Kanaseki, T., Hazama, A., and Okada, Y. (2000). Normotonic cell shrinkage because of disordered volume regulation is an early prerequisite to apoptosis. Proc. Natl. Acad. Sci. U.S.A. 97, 9487-9492. doi: $10.1073 /$ pnas. 140216197

Malli, R., Frieden, M., Osibow, K., and Graier, W. F. (2003). Mitochondria efficiently buffer subplasmalemmal $\mathrm{Ca}^{2+}$ elevation during agonist stimulation. J. Biol. Chem. 278, 10807-10815. doi: 10.1074/jbc.M21297 1200

Marsch, R., Foeller, E., Rammes, G., Bunck, M., Kössl, M., Holsboer, F., et al. (2007). Reduced anxiety, conditioned fear, and hippocampal long-term potentiation in transient receptor potential vanilloid type 1 receptor-deficient mice. J. Neurosci. 27, 832-839. doi: 10.1523/jneurosci.3303-06.2007

Movsesyan, V. A., Stoica, B. A., Yakovlev, A. G., Knoblach, S. M., Lea, P. M. Cernak, I., et al. (2004). Anandamide-induced cell death in primary neuronal cultures: role of calpain and caspase pathways. Cell Death Differ. 11, 1121-1132. doi: $10.1038 /$ sj.cdd.4401442

Olah, Z., Karai, L., and Iadarola, M. J. (2002). Protein kinase C(alpha) is required for vanilloid receptor 1 activation. Evidence for multiple signaling pathways. J. Biol. Chem. 277, 35752-35759. doi: 10.1074/jbc.M201551200

Olah, Z., Szabo, T., Karai, L., Hough, C., Fields, R. D., Caudle, R. M., et al. (2001). Ligand-induced dynamic membrane changes and cell deletion conferred by vanilloid receptor 1 . J. Biol. Chem. 276, 11021-11030. doi: 10.1074/jbc. M008392200

Olivero, P., Leiva-Salcedo, E., Devoto, L., and Stutzin, A. (2008). Activation of $\mathrm{Cl}^{-}$channels by human chorionic gonadotropin in luteinized granulosa cells of the human ovary modulates progesterone biosynthesis. Endocrinology 149, 4680-4687. doi: 10.1210/en.2008-0303

O’Neill, D. P., Peng, T., Stiegler, P., Mayrhauser, U., Koestenbauer, S., Tscheliessnigg, K., et al. (2011). A three-state mathematical model of hyperthermic cell death. Ann. Biomed. Eng. 39, 570-579. doi: 10.1007/s10439010-0177-1

Panayiotidis, M. I., Franco, R., Bortner, C. D., and Cidlowski, J. A. (2010). Ouabain-induced perturbations in intracellular ionic homeostasis regulate death receptor-mediated apoptosis. Apoptosis 15, 834-849. doi: 10.1007/ s10495-010-0494-8

Pecze, L., Blum, W., and Schwaller, B. (2013). Mechanism of capsaicin receptor TRPV1-mediated toxicity in pain-sensing neurons focusing on the effects of $\mathrm{Na}^{+} / \mathrm{Ca}^{2+}$ fluxes and the $\mathrm{Ca}^{2+}$-binding protein calretinin. Biochim. Biophys. Acta 1833, 1680-1691. doi: 10.1016/j.bbamcr.2012.08.018

Ramsey, I. S., Delling, M., and Clapham, D. E. (2006). An introduction to TRP channels. Annu. Rev. Physiol. 68, 619-647. doi: 10.1146/annurev.physiol.68. 040204.100431

Randhawa, P. K., and Jaggi, A. S. (2018). A review on potential involvement of TRPV1 channels in ischemia-reperfusion injury. J. Cardiovasc. Pharmacol. Ther. 23, 38-45. doi: 10.1177/1074248417707050

Rozas, P., Lazcano, P., Piña, R., Cho, A., Terse, A., Pertusa, M., et al. (2016). Targeted overexpression of tumor necrosis factor- $\alpha$ increases cyclin-dependent kinase 5 activity and TRPV1-dependent $\mathrm{Ca} 2+$ influx in trigeminal neurons. Pain 157, 1346-1362. doi: 10.1097/j.pain.000000000000 0527

Shimizu, T., Numata, T., and Okada, Y. (2004). A role of reactive oxygen species in apoptotic activation of volume-sensitive $\mathrm{Cl}^{-}$channel. Proc. Natl. Acad. Sci. U.S.A. 101, 6770-6773. doi: 10.1073/pnas.0401604101

Shin, C. Y., Shin, J., Kim, B.-M., Wang, M.-H., Jang, J.-H., Surh, Y.-J., et al. (2003). Essential role of mitochondrial permeability transition in vanilloid receptor 1-dependent cell death of sensory neurons. Mol. Cell. Neurosci. 24, 57-68. doi: 10.1016/S1044-7431(03)00121-0

Shirakawa, H., Yamaoka, T., Sanpei, K., Sasaoka, H., Nakagawa, T., and Kaneko, S. (2008). TRPV1 stimulation triggers apoptotic cell death of rat cortical neurons. Biochem. Biophys. Res. Commun. 377, 1211-1215. doi: 10.1016/j.bbrc.2008. 10.152 
Stutzin, A., and Hoffmann, E. K. (2006). Swelling-activated ion channels: functional regulation in cell-swelling, proliferation and apoptosis. Acta Physiol. 187, 27-42. doi: 10.1111/j.1748-1716.2006.01537.x

Sun, Z., Han, J., Zhao, W., Zhang, Y., Wang, S., Ye, L., et al. (2014). TRPV1 activation exacerbates hypoxia/reoxygenation-induced apoptosis in H9C2 cells via calcium overload and mitochondrial dysfunction. Int. J. Mol. Sci. 15, 18362-18380. doi: 10.3390/ijms151018362

Thomas, K. C., Sabnis, A. S., Johansen, M. E., Lanza, D. L., Moos, P. J., Yost, G. S., et al. (2007). Transient receptor potential vanilloid 1 agonists cause endoplasmic reticulum stress and cell death in human lung cells. J. Pharmacol. Exp. Ther. 321, 830-838. doi: 10.1124/jpet.107.119412

Tominaga, M., Caterina, M. J., Malmberg, A. B., Rosen, T. A., Gilbert, H., Skinner, K., et al. (1998). The cloned capsaicin receptor integrates multiple pain-producing stimuli. Neuron 21, 531-543. doi: 10.1016/S0896-6273(00)80 $564-4$

Utreras, E., Prochazkova, M., Terse, A., Gross, J., Keller, J., Iadarola, M. J., et al. (2013). TGF- $\beta 1$ sensitizes TRPV1 through Cdk5 signaling in odontoblast-like cells. Mol. Pain 9:24. doi: 10.1186/1744-8069-9-24

Varikmaa, M., Guzun, R., Grichine, A., Gonzalez-Granillo, M., Usson, Y., Boucher, F., et al. (2013). Matters of the heart in bioenergetics: mitochondrial fusion into continuous reticulum is not needed for maximal respiratory activity. J. Bioenerg. Biomembr. 45, 319-331. doi: 10.1007/s10863-012-9494-4
Wu, T. T., Peters, A. A., Tan, P. T., Roberts-Thomson, S. J., and Monteith, G. R. (2014). Consequences of activating the calcium-permeable ion channel TRPV1 in breast cancer cells with regulated TRPV1 expression. Cell Calcium 56, 59-67. doi: 10.1016/j.ceca.2014.04.006

Youle, R. J., and van der Bliek, A. M. (2012). Mitochondrial fission, fusion, and stress. Science 337, 1062-1065. doi: 10.1126/science.1219855

Ziglioli, F., Frattini, A., Maestroni, U., Dinale, F., Ciufifeda, M., and Cortellini, P. (2009). Vanilloid-mediated apoptosis in prostate cancer cells through a TRPV-1 dependent and a TRPV-1-independent mechanism. Acta Biomed. 80, $13-20$.

Conflict of Interest Statement: The authors declare that the research was conducted in the absence of any commercial or financial relationships that could be construed as a potential conflict of interest.

Copyright (C) 2018 Ramírez-Barrantes, Córdova, Gatica, Rodriguez, Lozano, Marchant, Echeverria, Simon and Olivero. This is an open-access article distributed under the terms of the Creative Commons Attribution License (CC BY). The use, distribution or reproduction in other forums is permitted, provided the original author(s) and the copyright owner are credited and that the original publication in this journal is cited, in accordance with accepted academic practice. No use, distribution or reproduction is permitted which does not comply with these terms. 